\title{
Ionic Oxidation in Cathodic Cage of Titanium CP Grade II
}

\author{
Jussier Oliveira Vitoriano ${ }^{,}$, Danilo Cavalcante Braz ${ }^{a}$, Geovani Ferreira Barbosa ${ }^{a}$, Francisco
}

\author{
Odolberto Araújo ${ }^{a}$, Clodomiro Alves Junior ${ }^{a}$
}

\author{
${ }^{a}$ Post-Graduate Program in Materials Science and Engineering, Universidade Federal Rural do Semi- \\ Árido, Brazil
}

Received: January 17, 2017; Revised: June 26, 2017; Accepted: July 26, 2017

\begin{abstract}
Titanium oxides such as rutile and anatase, are materials that stand out for exhibiting properties that act in biomedical and photocatalytic applications, among others. It is extreme importance to idealize new techniques that produce such compounds, being indispensable the improvement of characterizations for these materials. For this purpose, titanium comercially pure (CP) grade II cylindrical samples were oxidized ionically using titanium cage electric shields, oxidized at $350{ }^{\circ} \mathrm{C}$ in 3 and 8 hours. Through Grazing Incidence X-ray Diffraction (GIXRD) analysis, was observed on the surface of the treated samples the formation of a $\mathrm{TiO}_{2}$ film with the anatase, rutile and brookite phases, the latter phase cited being difficult to produce in conventional thermochemical treatments. All samples treated showed a significant increase in wettability using distilled water. The higer value was for the sample with a 8 hours treatment time, in which this condition presented phases with greater intensity in the analysis of GIXRD.
\end{abstract}

Keywords: Plasma, Cathodic cage, titanium, titanium oxide

\section{Introduction}

Titanium compounds are being extensively studied due to the large number of industrial applications, when elements such as hydrogen, carbon, nitrogen or oxygen are added in their crystalline lattice. The great affinity of titanium with these elements occurs because this metal has an incomplete electronic configuration, in other words, it has free "d" orbitals that promote the formation of chemical bonds with interstitial elements $(\mathrm{H}, \mathrm{C}, \mathrm{N} \text { and } \mathrm{O})^{1,2}$.

Titanium is also found in the form of oxide, the best known as $\mathrm{TiO}_{2}$. It is widely used because it is chemically inert and has characteristics such as biocompatibility, good dielectric properties, excellent absorption in the ultraviolet spectrum, high stability and is applied in different industrial areas such as solar cells, environmental purifiers, biomaterials, protective layers against corrosion, nanomaterials ${ }^{3-6}$. Among the existing titanium oxides compounds, titanium dioxide, $\mathrm{TiO}_{2}$, draws attention to possess important properties scientifically and industrially, and can be found in different crystalline structures, the best known being brookite, anatase and rutile. The anatase and rutile crystallizes in the tetragonal structure and brookite crystallizes in orthorhombic ${ }^{7-10}$.

In order to intensify the applications of titanium in industrial sectors, several processes have been developed in the areas of surface protection, electrical contacts, diffusion barriers, catalytic aspects, for example. This change of properties is explained by the overlap between the " $2 \mathrm{p}$ " orbitals of the interstitial elements such as oxygen, and the titanium $\mathrm{d}$ orbitals. In addition, in recent years, several researches have been conducted, mainly due to its biocompatibility and the sensitive modification of its properties, such as friction, optical absorption, hardness, wettability and wear, among others, when interstitial elements such as hydrogen, carbon, nitrogen or oxygen are introduced into their crystalline lattice ${ }^{11-14}$. This implies the importance of the need to control the composition and structure during the surface processing of titanium.

Among the current coating techniques for titanium surfaces, the cathodic cage has been gaining prominence due to its versatility. It was developed in the Laboratory of Plasma Materials Processing at UFRN (Labplasma) and emerged as an adaptation of ionic nitriding. Its main objective was to minimize some defects of the conventional technique, such as the edge effect, the opening of arcs, the effect of hollow cathode in samples with complex geometry. The cathodic cage is composed of a cylindrical plate and a cap, both with holes with similar diameters. The part to be treated is in floating potential, due to the presence of an insulating material between this and the cathode. In this way, the plasma is concentrated in the cage and not on the sample, producing the hollow cathode effect in the present holes. This effect causes the formation of a higher density of ions and these will react with the active species from the plasma used and these will be deposited by gravity and diffused in the part to be treated ${ }^{15-17}$.

Thus, the present work aims to propose a new technique for the production of $\mathrm{TiO}_{2}$ thin films by means of the cathodic 
cage plasma deposition technique, addressing the main parameters used in it.

\section{Materials and Methods}

For the preparation of the samples, titanium CP discs (Grade II) were used, measuring $15 \mathrm{~mm}$ in diameter and 1.5 $\mathrm{mm}$ in thickness. Before to plasma treatment, these were prepared metallographically by sanding with silicon carbide sticks having particle sizes 220, 360, 400, 600, 1200, 1500 and $2000 \mathrm{MESH}$. After sanding, a solution of hydrogen peroxide $(60 \%)$ and colloidal silica (40\%) was polished with an OP-CHEM polishing cloth for 30 minutes. Before the samples were inserted into the plasma reactor, these were cleaned by ultrasonic shaking in 3 different solution baths.

After cleaning, three samples were placed in a conventional stainless steel nitriding chamber with a $50 \mathrm{~mm}$ high $32 \mathrm{~mm}$ diameter top quartz window. For the treatment, was used a cathode cage made of titanium, presenting $70 \mathrm{~mm}$ of diameter and $34 \mathrm{~mm}$ of height, with 16 holes arranged laterally and $12.5 \mathrm{~mm}$ each. The cover of the cage had 12 holes with 12.5 $\mathrm{mm}$ diameter, as shown in Figure 1.

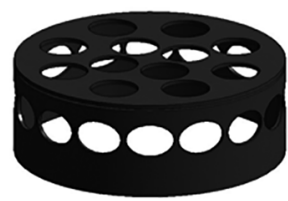

(a)

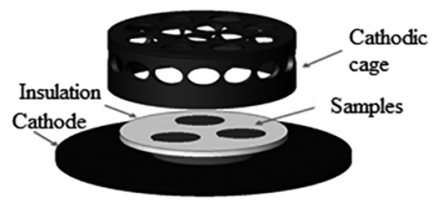

(b)
Figure 1. (a) Schematic representation of the cathodic cage (b) Arrangement of the samples in the cathodic cage.

All plasma interactions occur in the cathodic cage and not directly in the samples, being the last ones mentioned are in floating potential, isolated by an alumina disk. The cage works as the negative pole, the cathode, and the reactor chamber as the positive pole, the anode.

Initially, a cathodic cage cleaning was carried out in order to remove oxides or contaminants present on its surface, which consisted of a plasma treatment with argon and hydrogen gases, both with 10 SCCM (standard cubic centimeters per minute), pressure of $0.6 \mathrm{mbar}$ and temperature of $200^{\circ} \mathrm{C}$ for a time of 30 minutes. After this time, the thermochemical treatment was started in which it consisted of a flow of 20 SCCM of argon, pressure of 0.6 mbar at a temperature of $350^{\circ} \mathrm{C}$. Two groups of samples were treated, one with 3 hours of treatment and the other with 8 hours of treatment.

The GIXRD (Grazing Incidence X-ray Diffraction) analyzes were performed at CITED - UFERSA. The diffraction measurements were performed using a Shimadzu XRD diffractometer, model XRC-6000, in which were used the angles of incidence at $0.5^{\circ}, 1.0^{\circ}$ and $3.0^{\circ}, \mathrm{Cu} \mathrm{Ka}$ radiation in a $2 \theta$ scan of 20.0 to 80.0 , with $0.02^{\circ}$ step and counting time of 1 seconds. The identification of the phases was done with the help of the Match program, based on the American Mineralogist Crystal Structure Database (AMCSD), Crystallography Open Database (COD) and data obtained in the literature.

The contact angle was measured on 3 discs of each treated surface and standard, with the aid of a graduated pipette, $20 \mu \mathrm{L}$ of distilled water was dripped onto each disc. Photographs were obtained at different times until the complete relaxation of the drop (60 seconds), using a Pinnacle Studio 9.0 image capture program.

\section{Results and Discussions}

Figure 2 shows GIXRD diffractograms for standard samples and samples treated in 3 and 8 hours with a flow of 20 SCCM of argon. The GIXRD technique is important because of the small depth of beam penetration in the deposited layer, providing information about the diffusion profile that occurred in the treatment. It is shown a fundamental analysis for the present work, being more effective than the configuration of Bragg - Brentane. As the profile is small, the beam path should be small, reaching lower depths, which provides more information about the oxides layer formed.

Figure 2 (a) and 2 (b) show the standard sample diffractograms at an angle of $0.5^{\circ}$ and the treated samples at angles of $0.5^{\circ}, 1.0^{\circ}$ and $3.0^{\circ}$. In the standard sample, analyzed in $0.5^{\circ}$, are verified the presence of the phases of titanium and of two phases of rutile oxides in $35.59^{\circ}$ and $40.96^{\circ}$, being these last ones are due to the formation of the natural oxide layer, present in titanium and some transition metals ${ }^{1,2,7}$. These phases continue to be observed in the other depths of the beam in the treated samples. In Figure 2 (a) in the diffractogram, is observed the presence of the anatase, brookite and rutile phases of the sample treated for the angle of $0.5^{\circ}$, being the first and the last one more commonly found in works of the literature. Attention is drawn to the presence of the brookite phase that is formed under specific pressure conditions and lower temperatures, being difficult to produce in conventional thermochemical treatments ${ }^{12}$. This fact proves that superficially, the deposition process was effective, significantly modifying the surface treated sample.

With the increase of the beam depth, at the angles of $1.0^{\circ}$ and $3.0^{\circ}$, it's observed the intensity decrease of some phases present in the axis $2 \theta$, as the anatase in $25.39^{\circ}$, the brookite around $33.10^{\circ}$, and rutile at $54.30^{\circ}$ (Figure 2). The rutile phase at $27.47^{\circ}$, presents similar intensities in the angles of $0.5^{\circ}$ and $1.0^{\circ}$ and a slight decrease in $3.0^{\circ}$, which characterizes a greater formation stability of the same. On the other hand, other phases present an increase of the intensity according to the depth of the beam, can be these the anatase in $38.31^{\circ}$, and the rutile in $52.64^{\circ}$. The above facts can be explained by deposition preference of some phases in certain crystalline plains orientations, which occurs commonly in the deposition process of thin films. This fact can prove 


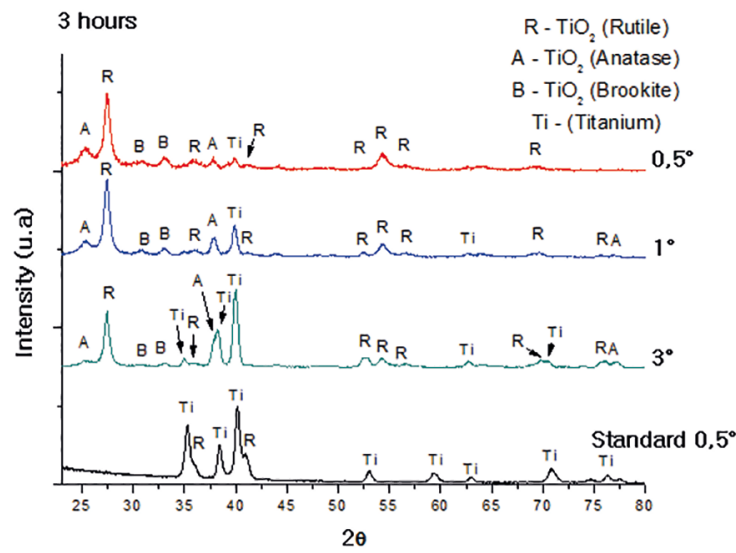

(a)

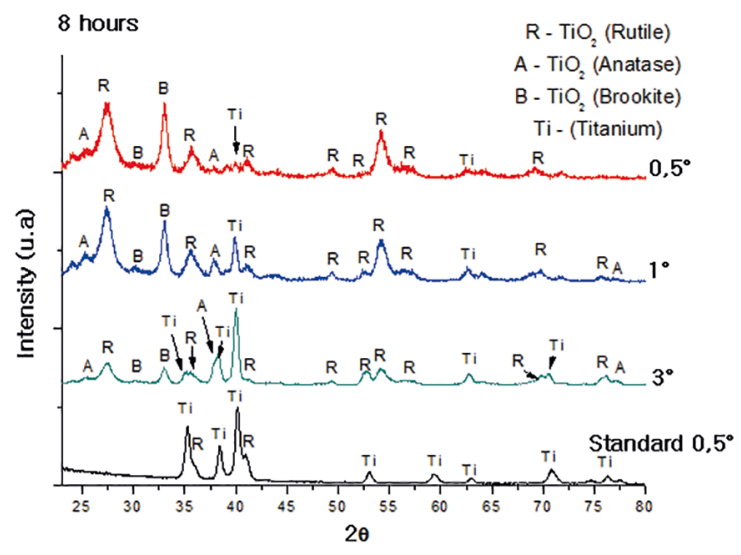

(b)

Figure 2. Diffractograms of the X-ray samples in GIXRD of the titanium samples. (a) treatment in 3, (b) treatment in 8 hours.

that the cathodic cage technique can promote the deposition process, because some titanium and titanium oxides phases are present in different depths and intensities.

An important point to be mentioned is that for the angle of $3^{\circ}$, some phases of titanium along with the phases of titanium oxides present are observed. This can be explained by the fact that the $3^{\circ}$ beam is obtaining information from the deposited film and also from the substrate providing this peak with the two phases present. As around $38^{\circ}$ the phase of titanium and anatase are in the same peak, and for the angles of $1.0^{\circ}$ and $0.5^{\circ}$ only the presence of the anatase phase is verified, indicating that the beam obtained more information from the deposited film. In the same way occurs around $70^{\circ}$ for the rutile and titanium phases.

In Figure 2(b), the first important observation is the presence of phases with higher intensities, which can be explained due to the longer treatment time, resulting in higher deposition kinetics. The presence of the brookite phase becomes more evident for this time of treatment, although it is a difficult phase to obtain the titanium oxide. For both Figure 2 (a) and Figure 2 (b) =, at the $0.5^{\circ}$ angle for the standard sample and treated, a significant difference between the present phases is observed, with the oxide phases prevailing.

Again is observed the preference of some phases according to depth. In relation to the decrease in intensity with the depth of the beam, the same phases cited for the treatment of 3 hours, such as anatase at $25.39^{\circ}$, brookite at around $33.10^{\circ}$, and rutile at $54.30^{\circ}$, behaved in this way. And in relation to the intensity increase with the beam depth, similar to the 3-hour treatment, the phases that presented this behavior were the anatase at $38.31^{\circ}$, and the rutile at $52.64^{\circ}$, drawing attention only by the difference of intensity between treatments of 3 and 8 hours. It is also observed in both treatments, for the angle of $3^{\circ}$ the appearance of the phases of titanium in dispute with anatase phase, because it verified the presence of two phases in a same peak.
An important fact to be mentioned is that the deposition process of titanium oxides was effective even at a relatively low temperature, that is, at $350^{\circ} \mathrm{C}$. It also occurs due to the high affinity of the titanium with oxygen, where the pressure and temperature conditions caused the formation of the different crystalline phases, rutile, anatase and brookite. The same occurred using only the argon gas and residual oxygen present in the reactor, and these conditions may have favored the formation of the brookite phase. Another important point is the cathodic deposition technique, which, although the particle shock did not occur directly on the surface of the sample, but in the cage, where the hollow cathode effect present in the holes of the cage and together with the temperature and pressure parameters, may also have provided formation kinetics for the brookite phase $\mathrm{e}^{15-17}$.

According to the results of the contact angle, shown in Figure 3 and Figure 4, the tendency of the reduction of the angle of contact with the treatment time can be mentioned as the main point. The result for the untreated sample presented an angle value around $63.00 \pm 4.00$, presenting a hydrophilic character due to the value being smaller than $90^{\circ}$ which is already characteristic of titanium samples with the preparation performed in the present work ${ }^{12}$.

The sample with 3 hours of treatment obtained a value of $32.66 \pm 2.52$ and the sample with 8 hours of treatment $6.33 \pm 0.58$, observing a considerable decrease of the angle of contact with the treatment time. These changes related to the hydrophilic character, refer to the presence of different crystalline phases of titanium oxides, which increases the ability of the samples to interact with the distilled water. By relating the value of the contact angle for the sample treated with 8 hours with Figure 2 (b), this decrease of the contact angle can be related to the increase of the intensities presented in the diffractograms. 


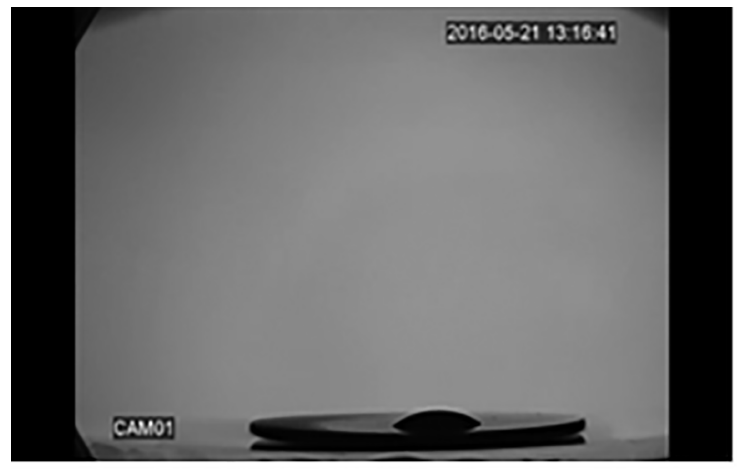

(a)

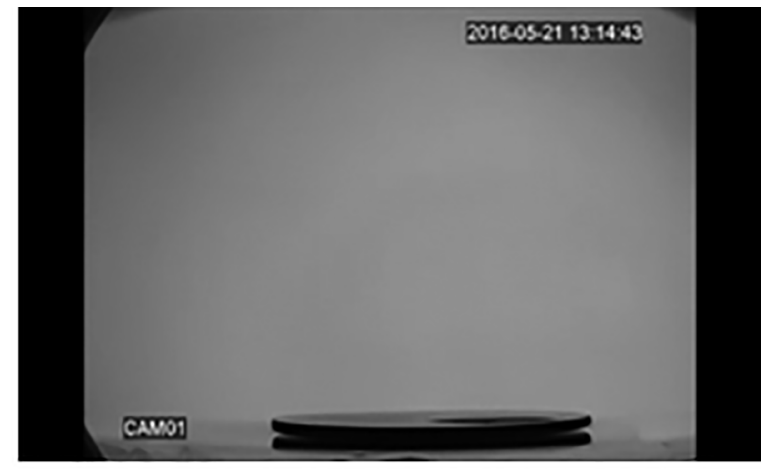

(b)

Figure 3. Wettability test of titanium surfaces. (a) treated in 3 hours, (b) treated in 8 hours.

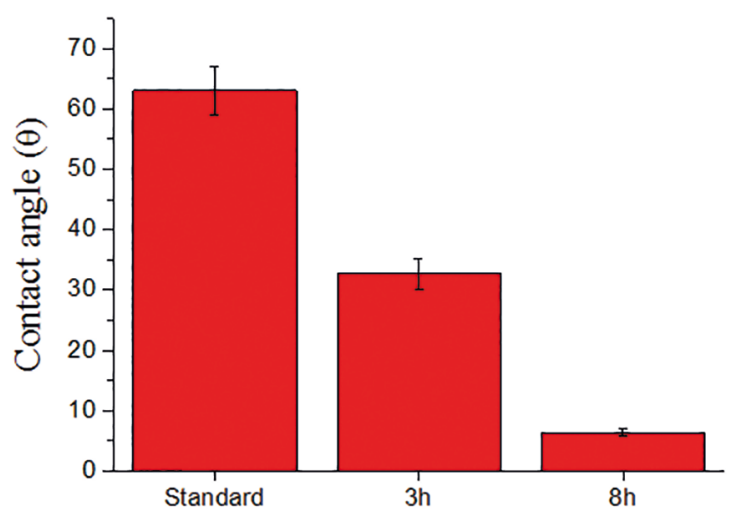

Figure 4. Graph of contact angle analysis for untreated and treated samples.

\section{Conclusions}

The cathodic cage plasma deposition technique proved to be effective in the deposition of different titanium oxides directly on grade II titanium parts. The same was done at a lower temperature of $350^{\circ} \mathrm{C}$ when compared to other thermochemical treatments by plasma and caused a higher rate of deposition with a longer treatment time. In addition to the titanium oxide phases most commonly observed in the literature, it was obtained the brookite phase in which it may have been formed due to kinetics of the plasma in the hollow cathode effect together with the parameters of pressure, temperature and gas flow. The contact angle was a property that obtained a significant change when compared with the standard sample, collaborating with the confirmation of the efficiency of the treatment.

\section{References}

1. Feltrin J, Sartor MN, De Noni Jr. A, Bernardin AM, Hotza D, Labrincha JA. Superfícies fotocatalíticas de titânia em substratos cerâmicos. Parte I: Síntese, estrutura e fotoatividade. Cerâmica. 2013;59(352):620-632.
2. Joshi VA. Titanium Alloys - An Atlas of Structures and Fracture Features. Boca Raton: CRC Press Taylor \& Francis; 2006.

3. Vitoriano JO, Alves Jr. C, Braz DC, Rocha HA, Silva RCL. In vitro study of platelet behaviour on titanium surface modified by plasma. Ciência \& Tecnologia dos Materiais. 2017;29(1):130134.

4. Aires MM, Treter J, Braz DC, Krug C, Macedo AJ, Alves Júnior C. Influence of Oxynitrided Surface in the Production of a Less Susceptible Titanium Surface to Skin-Borne Bacterial Adhesion. Artificial Organs. 2016;40(5):521-526.

5. Nunes Filho A, Braz DC, Hinrichs R, Vasconcelos MAZ, Rocha RCS, Alves Júnior C. Estudo da influência dos padrões de emissão das espécies do plasma de carbonitretação nas propriedades superficiais de TiCN. Matéria (Rio de Janeiro). 2015;20(1):72-82.

6. Kazemeini MH, Berezin AA, Fukuhara N. Formation of thin $\mathrm{TiN}_{\mathrm{x}} \mathrm{O}_{\mathrm{y}}$ films by using a hollow cathode reactive DC sputtering system. Thin Solid Films. 2000;372(1-2):70-77.

7. Landmann M, Rauls E, Rauls WG. The electronic structure and optical response of rutile, anatase and brookite $\mathrm{TiO}_{2}$ Journal of Physics: Condensed Matter. 2012;24(19):195503.

8. Trenczek-Zajac A, Kowalski K, Zakrzewska K, Radecka M. Nitrogen-doped titanium dioxide-Characterization of structural and optical properties. Materials Research Bulletin. 2009;44(7):1547-1552.

9. Xing M, Zhang J, Chen F. New approaches to prepare nitrogendoped $\mathrm{TiO}_{2}$ photocatalysts and study on their photocatalytic activities in visible light. Applied Catalysis B: Environmental. 2009;89(3-4):563-569.

10. Sirghi L, Aoki T, Hatanaka Y. Diagnostics of the radio frequency magnetron discharge plasma used for $\mathrm{TiO}_{2}$ thin film sputtering deposition. Surface and Coatings Technology. 2004;187(23):358-363.

11. Liu X, Chu PK, Ding C. Surface modification of titanium, titanium alloys, and related materials for biomedical applications. Materials Science and Engineering: R: Reports. 2004;47(34):49-121. 
12. Braz DC, Barbosa JCP, Nunes Filho A, Rocha RCS, Silva DR, Alves Júnior C. Influência das espécies do plasma na modificação das propriedades superficiais do titânio tratado por plasma de $\mathrm{N}_{2}-\mathrm{Ar}-\mathrm{O}_{2}$ Matéria (Rio de Janeiro). 2012;17(2):1035-1044.

13. Silva MAM, Guerra Neto CLB, Nunes Filho A, Freitas DO, Braz DC, Alves Júnior C. Influence of topography on plasma treated titanium surface wettability. Surface and Coatings Technology. 2013;235:447-453.

14. Riedel NA, Smith BS, Williams JD, Popat KC. Improved thrombogenicity on oxygen etched $\mathrm{Ti}_{6} \mathrm{Al}_{4} \mathrm{~V}$ surfaces. Materials Science and Engineering: C. 2012;32(5):1196-1203.
15. AlvesJúnior C. Nitretação a Plasma: Fundamentos e Aplicações . Natal: EDUFRN; 2001.

16. Daudt NF, Barbosa JCP, Braz DC, Pereira MB, Alves Júnior C. TiN thin film deposition by cathodic cage discharge: effect of cage configuration and active species. Journal of Physics: Conference Series. 2012;406:012021.

17. Sousa RRM, Araújo FO, Costa THC, Nascimento IO, Santos FEP, Alves Júnior C, et al. Thin Tin and $\mathrm{Tio}_{2}$ Film Deposition in Glass Samples by Cathodic Cage. Materials Research. 2015;18(2):347-352. 